\title{
Measurement of Soluble Arsenic in Soil of Bangladesh by Acid-alkali Sequential Extraction
}

\author{
Md. Shafiul Azam ${ }^{1}$, Md. Shafiquzzaman ${ }^{1}$, Iori Mishima ${ }^{2}$, and Jun Nakajima ${ }^{1}$ \\ ${ }^{1}$ Dept. of Environmental System Engineering, Ritsumeikan University, 1-1-1 Nojihigashi, Kusatsu, \\ Shiga 525-8577, Japan \\ ${ }^{2}$ Center for Environmental Science in Saitama, Japan; 914 Kamitanadare, Kisai, Kitasaitamagun \\ 347-0115, Japan
}

Received 20 August 2008, accepted in final revised form 6 November 2008

\begin{abstract}
To measure easily soluble fraction of arsenic, a sequential extraction method by $0.1 \mathrm{~N} \mathrm{HCl}$ and $0.1 \mathrm{~N} \mathrm{NaOH}$ was used according to the soil phosphorus extraction procedure. The effects of reducing conditions on arsenic extraction were examined in incubation test. In high reducing conditions arsenic solubility was shown to be high and seemed to be controlled by dissolution of iron oxy-hydroxides. $\mathrm{pH}$ played a predominant role in determining the concentrations of soluble arsenic. Arsenic solubility could be possible at low or high $\mathrm{pH}$ conditions. Released arsenic in different $\mathrm{pH}$ and redox conditions showed that it is a part of acid extractable arsenic which is sorbed weakly on the soil surface and can be extracted during acid-alkali sequential extraction. Therefore, the method could be applicable to measure potential solubility of arsenic as a result of alteration in soil (e.g. redox, $\mathrm{pH}$ ) and environmental factors. Sequential extraction results of the soil samples collected in dry and wet season suggested that acid-alkali extracted arsenic fractions of surface and core soil samples of paddy field were increased in wet season. They seemed to be moved with irrigation groundwater.

Keywords: Acid-alkali extraction; Arsenic contamination; Soil arsenic mobility; Groundwater contamination; Paddy soil.

(C) 2009 JSR Publications. ISSN: 2070-0237(Print); 2070-0245 (Online). All rights reserved.

DOI: $10.3329 /$ jsr.vlil.1058
\end{abstract}

\section{Introduction}

Arsenic (As) is potentially harmful to human health. It causes various diseases like skin and lung cancer [1]. Elevated concentrations of As in sediments can occur due to natural or anthropogenic processes. Recently extensive As contamination of groundwater in alluvial sediments has been identified in areas such as Bangladesh, Taiwan, Argentina, Nepal, USA, Vietnam, and West Bengal of India [2]. Tens of millions of people are potentially at risk from the consumption of high As groundwater in these regions. In

\footnotetext{
${ }^{1}$ Corresponding author: shiponb@yahoo.com
} 
Bangladesh alone, 40 million people are believed to be at risk to As poisoning [3]. Rising demand of food production in densely populated countries like India and Bangladesh enhanced the use of As contaminated groundwater for irrigation leaving soil increasingly As rich. In addition to concerns over As contamination in water sources, it also alarms that dietary intake of As from contaminated soils [4] through the food chain may adversely affect human health [5]. Therefore, As mobility release and extraction from contaminated soil are topics of significant importance.

The prevalent mechanism of As mobilization is reductive dissolution of iron oxyhydroxides and release of sorbed As [6]. Mobility and transport of As in the environment are strongly influenced by its adsorption/desorption in soil and sediment. It is generally recognized that total As concentration in the soil is not necessarily a good indicator of potential bioavailability or mobility. To predict As mobility accurately, it is necessary to quantify its association with soil and sediment. The use of sequential extraction techniques to fractionate metals in solid materials has become widely used and well recognized [7-9]. They have been used to measure heavy metals in ion-exchangeable, adsorbed on the surface, precipitated and organic bounded fractions. Some researchers believe that soil extraction schemes employed for phosphorus $(\mathrm{P})$ fractionation are more suitable for As [10-12] because As and $\mathrm{P}$ form similar oxyanions in the +5 oxidation state in soils [13] and behave similarly in well aerated soils [14]. Several multi-step extraction methods were used for fractionation of As but an inherent problem with these method was re-adsorption of As to soil residue [15-17]. This limitation shows the need for the development of a more efficient sequential extraction method for As that extracts As bound to soil constituents.

The main aim of this study was to measure potentially mobilizable and easily soluble As in soil and sediment by applying a simple two step acid-alkali $(0.1 \mathrm{~N} \mathrm{HCl}$ and $0.1 \mathrm{~N}$ $\mathrm{NaOH}$ ) sequential extraction method according to the soil $\mathrm{P}$ extraction procedure used for the measurement of bioavailable phosphorus (BAP) [18]. A number of paddy field and pond sediment samples of Bangladesh were analyzed in this study.

\section{Materials and Methods}

\subsection{Sample collection and preparation}

Soil samples were collected from different groundwater arsenic contaminated sites in Khulna, southwestern region of Bangladesh. Being located in the downstream of the mighty rivers, the Ganges and the Brahmaputra a part of the sediments carried is deposited in the flood plains of the country each year [19]. Generally in Bangladesh paddy fields are irrigated with groundwater between January and May and an estimated $1000 \mathrm{t}$ of As is pumped directly onto the rice fields [20]. Fig. 1 shows the map of the sampling sites. The paddy fields are located in Rupsha, Fakirhat and Mollahat which are sub-districts of Bagerhat district. Samples were collected in December of 2005 (dry season) indicated by D and September of 2006 (wet season) indicated by S. In dry season core samples (0 20 
$\mathrm{cm}, 20 \sim 40 \mathrm{~cm}, 40 \sim 60 \mathrm{~cm}, 60 \sim 80 \mathrm{~cm}$ and $80 \sim 100 \mathrm{~cm}$ ) were taken in one sampling point at each of the five paddy field sites (D-1 to D-5) and one pond site (D-6). In wet season each of the three paddy field sites (S-1 to S-3) and two pond sites (S-4 and S-5) had one core sampling point $(0 \sim 10 \mathrm{~cm}, 10 \sim 20 \mathrm{~cm}, 20 \sim 40 \mathrm{~cm}$ and 40 60 cm). From same sites both in dry and wet season, samples were collected which were D-1, S-2 and D-4, S-3 and one surface soil sample from an irrigation channel in dry (D-IC) and wet (S-IC) season.

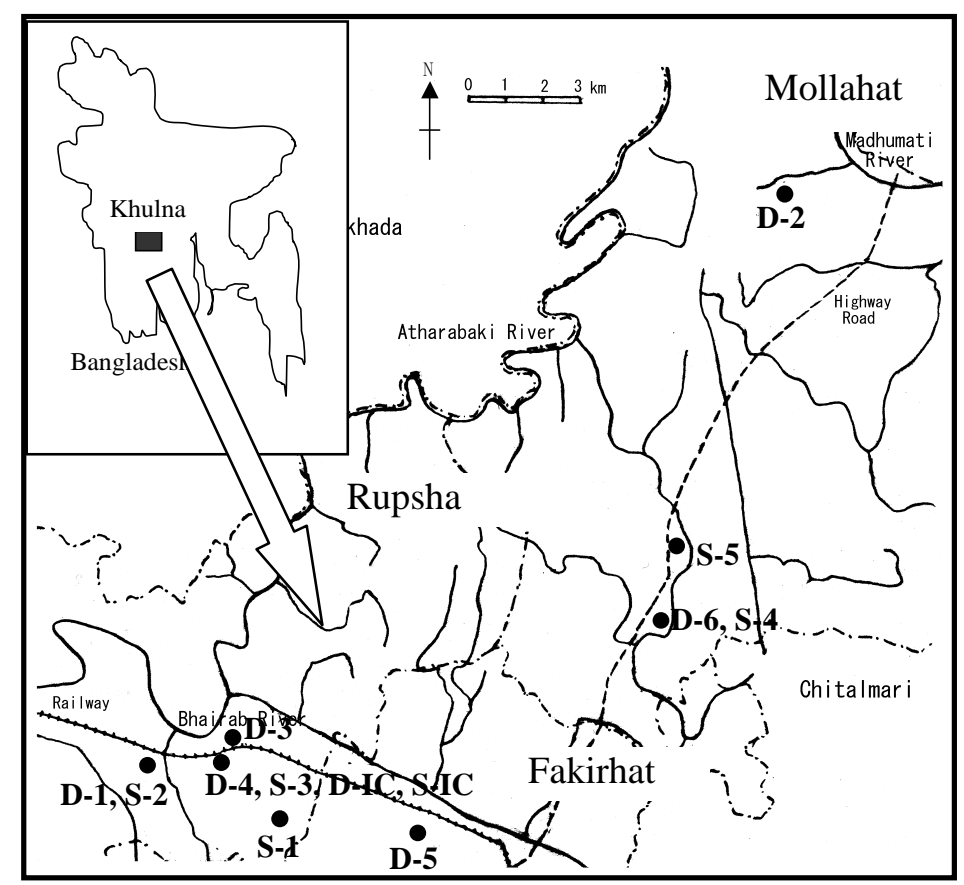

Fig. 1. Geographical locations of sampling site.

Moisture content (MC) of the soil samples was measured in the laboratory of Khulna University of Engineering and Technology (KUET), Bangladesh on the same day of the collection. Samples were air-dried and homogenized by mixing and brought back to Japan packing with polyethylene bags. Air- dried soil samples were ground and passed through a $0.5 \mathrm{~mm}$ sieve to separate coarse debris.

\subsection{Batch experiment}

The samples of soil and sediments taken at site D-4, D-6, S-3 and D-IC were used for the following batch experiments. Soil samples with high and low content of As from both paddy soil and sediment samples were used for understanding clearly the behavior of As 
in different conditions.

\subsubsection{Effect of anaerobic incubation}

Batch release experiment was conducted to measure the amount of As solubility in various conditions of redox potential. The batch experiment was initiated by taking $1.0 \mathrm{~g}$ of soil into different air tight glassware bottles and filled with $100 \mathrm{ml}$ of glucose solution (100 $\mathrm{mg} / \mathrm{L}$ ) as a source of carbon for soil microorganisms, to promote the development of reducing conditions and shaken for 0, 5, 10 and 15 days at $250 \mathrm{rpm}$. ORP and pH were measured before and after shaking. On completion of the shaking the mixed liquor in the bottles was filtered through a $1.0 \mu \mathrm{m}$ Advantec 5C filter paper. Then the soil residue with the filter paper was extracted by sequential acid-alkali extraction method and percentages of the released and extracted As were estimated. The experiment was conducted in the laboratory under room temperature.

\subsubsection{Effect of $p H$}

Batch $\mathrm{pH}$ experiment was conducted to understand the effect of $\mathrm{pH}$ on the extraction. 1.0 $\mathrm{g}$ of soil sample was taken into different Teflon bottles and shaken for 24 hrs at $140 \mathrm{rpm}$ after adding $100 \mathrm{ml}$ of $\mathrm{NaHCO}_{3}$ buffer solution $(10 \mathrm{~g} / \mathrm{L})$. pH of buffer solution was adjusted to 1.0, 3.0, 5.0, 7.0, 9.0, 11.0 and 13.0 before adding with soil. After shaking $\mathrm{pH}$ and ORP of the mixed liquor was measured and was filtered through $1.0 \mu \mathrm{m}$ Advantec 5C filter paper. The soil residue with the filter paper was extracted by the sequential acid-alkali extraction method and percentages of the released and extracted As and Fe were estimated. The experiment was conducted in the laboratory under room temperature.

\subsection{Acid-alkali extraction}

Extraction experiments were initiated by taking $1.0 \mathrm{~g}$ of oven-dried soil into a Teflon bottle and mixed with $50 \mathrm{ml}$ of $0.1 \mathrm{~N} \mathrm{HCl}$ and shaken for 3 minutes at $200 \mathrm{rpm}$. The acid extract was obtained by filtration through No. $5 \mathrm{C}$ filter paper. As, $\mathrm{P}$ and Fe in the filtrate were measured (HCl-As, HCl-P and HCl-Fe). The residue of the filtration with the filter paper was then put into the same bottle mixed with $100 \mathrm{ml}$ of $0.1 \mathrm{~N} \mathrm{NaOH}$ and was shaken for $17 \mathrm{hrs}$ at $140 \mathrm{rpm}$. The alkali extract was obtained by centrifuge and filtration through $1.0 \mu \mathrm{m}$ Advantec 5C filter paper. As, $\mathrm{P}$ and $\mathrm{Fe}$ in the filtrate were measured ( $\mathrm{NaOH}-\mathrm{As}$, $\mathrm{NaOH}-\mathrm{P}$ and $\mathrm{NaOH}-\mathrm{Fe}$ ). Residual fraction (Res.) was determined as the difference between total and extracted fractions.

For examining the effect of extraction time $1.0 \mathrm{~g}$ of the dried sample was put in the bottle and extracted during 3 minutes, 10 minutes, 30 minutes, 1 hour, 3 hours and 17 hours using $50 \mathrm{ml}$ of $0.1 \mathrm{~N} \mathrm{HCl}$ and $100 \mathrm{ml}$ of $0.1 \mathrm{~N} \mathrm{NaOH}$ separately. Duplicate examination was carried out for each extraction. The experiment was conducted in the laboratory under room temperature. 


\subsection{Analytical method}

Arsenic standard stock solution of internal standard (1000 ppm), $\mathrm{HCl}(35 \%), \mathrm{HNO}_{3}$ (60\%), $\mathrm{H}_{2} \mathrm{SO}_{4}$ (97\%), $\mathrm{NaOH}(96 \%)$ and DDTC-Ag were purchased from Nacalai tesque. Inc. Kyoto, Japan. Iron, Phosphorus stock solution (1000 ppm) and $\mathrm{NaHCO}_{3}$ (99.5\%) were obtained from Wako Pure Chemical Industries Ltd. Japan. Fresh calibration standards were prepared by diluting analytical standards in 5\% nitric acid. Particle size distribution was measured by the laser diffraction method (Shimadzu SALD 3000). Soil pH was determined with 1:2 soil/water suspension using $\mathrm{pH}$ meter (Horiba, Japan). Oxidation reduction potential (ORP) was measured by UC-23 Digital pH/ORP meter (CKC) and converted to Eh. Organic matter (OM) was determined by the percentage of weight loss after ignition $\left(600^{\circ} \mathrm{C}\right.$ for $1 \mathrm{hr}$ ). Total concentration of arsenic (T-As), phosphorus (T-P), and iron (T-Fe) were measured after hot acid digestion with $\mathrm{H}_{2} \mathrm{SO}_{4}$ and $\mathrm{HNO}_{3}$. T-As was determined by DDTC-Ag colorimetric method (JIS K 0102). HCl-As and NaOH-As were determined by graphite furnace atomic absorption spectrometry (GF-AAS) (Hitachi Z2700). Due to the interference of sulfur in the soil solution obtained during the acid digestion T-As was not measured by GF-AAS. T-P, HCl-P and NaOH-P were determined by Molybdenum blue colorimetric method (JIS K 0102). T-Fe, HCl-Fe and NaOH-Fe were determined by inductively coupled plasma atomic emission spectrometry (ICP-AES) (Seiko SPS 4000). All measurements were carried out in triplicate including appropriate reagent blanks.

\section{Results and Discussions}

\subsection{Arsenic concentrations and properties of soil}

It has been reported that soil composition, such as contents of clay, OM, Fe, P, and soil properties, such as $\mathrm{pH}$ are the major controlling factors for trace metal concentrations in soils [21]. In the current study, contents of clay, OM, T-Fe, T-P and $\mathrm{pH}$ in soil of different sites in dry and wet season varied greatly (Table 1).

Soil $\mathrm{pH}$ indicated that almost all site samples were moderately alkaline with the exception of surface layer of D-5, 80 100 cm layer of D-6, D-IC, S-IC and site S-4 that had neutral or moderately acidic soil. MC showed almost uniform distribution in almost all the sites. It varied from $21 \%$ to $46 \%$ and pond site D-6, S- 4 and paddy field S-1, S-2, and S-3 covered with water during wet season had higher MC value. OM content ranged between 1.8 and 9.6\% with D-IC, S-IC, D-6 and S-4 had higher values. It showed almost uniform and slightly decreased in subsoil samples except in D-6 and S-4 that had higher $\mathrm{OM}$ in subsoil than surface. OM accumulation in pond sediment seemed to be caused by much amount of algae, and fish in the pond and biological decomposition in the deep layers. While in irrigation channel it seemed to be due to irrigation water. T-Fe ranged from 6.41 to $44.9 \mathrm{mg} / \mathrm{g}$ and T-P ranged from 0.29 to $1.70 \mathrm{mg} / \mathrm{g}$. Same soil samples in wet season had higher T-Fe and T-P content than that in dry season. T-Fe and T-P content of paddy field site and irrigation channel were high seemed to be due to the influence of irrigation water. T-As ranged from 4.42 to $21.0 \mu \mathrm{g} / \mathrm{g}$ except D-IC and S-IC which had 
high concentration. Average As content in Bangladesh soil is less than $10 \mu \mathrm{g} / \mathrm{g}$ [22]. As compared to average value T-As contents in some paddy field soil were high.

In general paddy field samples contained higher T-As than pond sediment because of As accumulation during irrigation. Among the paddy field sites D-5 had low T-As seemed to be due to low clay content. D-6 had higher T-As than other pond site (S-4 and S-5) probably due to utilization of D-6 as paddy field by rotation and subjected to irrigation very year. Regarding soil depth there was little or no trend in T-As. Layer 80 100 cm of

Table 1. Characteristics of soil samples in dry and wet season.

\begin{tabular}{|c|c|c|c|c|c|c|c|c|}
\hline $\begin{array}{c}\text { Site } \\
\text { name }\end{array}$ & $\begin{array}{l}\text { Depth } \\
\text { (cm) }\end{array}$ & $\mathrm{pH}$ & $\begin{array}{l}\text { MC } \\
(\%)\end{array}$ & $\begin{array}{l}\text { OM } \\
(\%)\end{array}$ & $\begin{array}{l}\text { Clay } \\
(\%)\end{array}$ & $\mathrm{T}-\mathrm{Fe}(\mathrm{mg} / \mathrm{g})$ & T-P (mg/g) & T-As $(\mu \mathrm{g} / \mathrm{g})$ \\
\hline \multirow[t]{5}{*}{ D-1 } & $0 \sim 20$ & 8.58 & 31 & 5.6 & 22.5 & $25.7 \pm 4.8$ & $0.29 \pm 0.01$ & $11.4 \pm 1.2$ \\
\hline & $20 \sim 40$ & 8.50 & 28 & 5.1 & 29.9 & $13.2 \pm 2.1$ & $0.39 \pm 0.01$ & $12.9 \pm 0.8$ \\
\hline & $40 \sim 60$ & 8.74 & 27 & 4.5 & 26.4 & $22.0 \pm 2.2$ & $0.45 \pm 0.00$ & $11.9 \pm 0.5$ \\
\hline & $60 \sim 80$ & 8.77 & 30 & 4.9 & 25.0 & $6.41 \pm 1.5$ & $0.46 \pm 0.01$ & $11.5 \pm 1.4$ \\
\hline & 80 100 & 8.86 & 31 & 4.9 & 28.0 & $19.1 \pm 2.0$ & $0.45 \pm 0.00$ & $12.1 \pm 0.1$ \\
\hline \multirow[t]{5}{*}{ D-2 } & $0 \sim 20$ & 8.61 & 29 & 5.1 & 13.9 & $19.1 \pm 5.3$ & $0.67 \pm 0.01$ & $8.70 \pm 0.1$ \\
\hline & $20 \sim 40$ & 8.67 & 30 & 4.9 & 19.8 & $12.8 \pm 0.3$ & $0.58 \pm 0.00$ & $9.94 \pm 0.2$ \\
\hline & $40 \sim 60$ & 8.71 & 32 & 5.1 & 30.5 & $25.3 \pm 0.0$ & $0.54 \pm 0.00$ & $8.40 \pm 0.8$ \\
\hline & $60 \sim 80$ & 8.76 & 29 & 4.8 & 25.7 & $12.5 \pm 0.6$ & $0.50 \pm 0.01$ & $8.71 \pm 0.6$ \\
\hline & $80 \sim 100$ & 8.83 & 29 & 4.0 & 22.5 & $26.0 \pm 0.2$ & $0.48 \pm 0.01$ & $9.06 \pm 0.1$ \\
\hline \multirow[t]{5}{*}{ D-3 } & $0 \sim 20$ & 7.56 & 27 & 4.5 & 26.4 & $12.2 \pm 3.5$ & $0.42 \pm 0.01$ & $9.44 \pm 1.3$ \\
\hline & $20 \sim 40$ & 7.64 & 28 & 4.6 & 25.0 & $28.6 \pm 1.7$ & $0.39 \pm 0.01$ & $11.1 \pm 0.6$ \\
\hline & $40 \sim 60$ & 8.21 & 26 & 4.4 & 13.9 & $24.7 \pm 1.3$ & $0.45 \pm 0.01$ & $11.8 \pm 0.4$ \\
\hline & $60 \sim 80$ & 7.53 & 27 & 4.4 & 19.8 & $25.2 \pm 0.7$ & $0.48 \pm 0.02$ & $11.9 \pm 1.0$ \\
\hline & $80 \sim 100$ & 8.67 & 29 & 4.4 & 21.3 & $10.5 \pm 0.3$ & $0.42 \pm 0.00$ & $10.8 \pm 0.3$ \\
\hline \multirow[t]{5}{*}{ D-4 } & $0 \sim 20$ & 7.64 & 26 & 5.3 & 31.0 & $13.4 \pm 1.9$ & $0.31 \pm 0.01$ & $12.1 \pm 1.4$ \\
\hline & $20 \sim 40$ & 8.16 & 37 & 3.4 & 33.1 & $15.7 \pm 2.6$ & $0.38 \pm 0.02$ & $10.3 \pm 0.6$ \\
\hline & $40 \sim 60$ & 8.22 & 26 & 3.4 & 29.9 & $20.3 \pm 0.6$ & $0.37 \pm 0.02$ & $9.65 \pm 0.4$ \\
\hline & $60 \sim 80$ & 8.25 & 24 & 2.9 & 28.3 & $17.4 \pm 3.5$ & $0.41 \pm 0.03$ & $8.22 \pm 0.2$ \\
\hline & $80 \sim 100$ & 8.15 & 23 & 3.3 & 30.6 & $13.6 \pm 4.7$ & $0.44 \pm 0.02$ & $8.09 \pm 0.3$ \\
\hline \multirow[t]{5}{*}{ D-5 } & $0 \sim 20$ & 7.17 & 21 & 2.6 & 0.80 & $15.7 \pm 0.3$ & $0.38 \pm 0.05$ & $4.67 \pm 0.7$ \\
\hline & $20 \sim 40$ & 8.37 & 23 & 3.5 & 0.15 & $15.5 \pm 0.2$ & $0.46 \pm 0.01$ & $6.82 \pm 0.2$ \\
\hline & $40 \sim 60$ & 8.28 & 24 & 3.1 & 0.24 & $20.5 \pm 0.8$ & $0.47 \pm 0.01$ & $7.23 \pm 0.1$ \\
\hline & $60 \sim 80$ & 7.94 & 24 & 2.0 & 1.33 & $25.6 \pm 3.1$ & $0.46 \pm 0.01$ & $6.29 \pm 0.1$ \\
\hline & $80 \sim 100$ & 8.53 & 23 & 1.8 & 0.63 & $19.1 \pm 1.8$ & $0.42 \pm 0.00$ & $4.42 \pm 0.1$ \\
\hline \multirow[t]{5}{*}{ D-6 } & $0 \sim 20$ & 8.77 & 31 & 4.6 & 18.3 & $16.6 \pm 0.3$ & $0.46 \pm 0.01$ & $7.37 \pm 0.2$ \\
\hline & $20 \sim 40$ & 8.61 & 36 & 5.8 & 25.3 & $28.7 \pm 1.4$ & $0.42 \pm 0.01$ & $8.60 \pm 0.2$ \\
\hline & $40 \sim 60$ & 7.81 & 36 & 7.0 & 58.6 & $17.1 \pm 1.2$ & $0.43 \pm 0.02$ & $5.45 \pm 0.1$ \\
\hline & $60 \sim 80$ & 8.02 & 34 & 4.9 & 12.8 & $20.3 \pm 1.2$ & $0.41 \pm 0.01$ & $7.76 \pm 0.8$ \\
\hline & 80 100 & 5.37 & 46 & 8.4 & 51.1 & $16.5 \pm 1.8$ & $0.41 \pm 0.01$ & $15.1 \pm 0.9$ \\
\hline
\end{tabular}




\begin{tabular}{|c|c|c|c|c|c|c|c|c|}
\hline D-IC & $0 \sim 20$ & 6.95 & 25 & 7.1 & 7.9 & $21.2 \pm 7.6$ & $0.75 \pm 0.08$ & $60.9 \pm 1.6$ \\
\hline \multirow[t]{4}{*}{ S-1 } & $0 \sim 10$ & 8.07 & 29 & 6.2 & 13.9 & $21.0 \pm 0.9$ & $0.96 \pm 0.03$ & $17.2 \pm 0.4$ \\
\hline & 10 20 & 7.87 & 35 & 5.6 & 19.8 & $20.7 \pm 1.4$ & $1.01 \pm 0.01$ & $21.0 \pm 0.1$ \\
\hline & $20 \sim 40$ & 8.10 & 27 & 4.8 & 30.5 & $27.6 \pm 7.6$ & $0.51 \pm 0.01$ & $11.4 \pm 1.9$ \\
\hline & $40 \sim 60$ & 8.55 & 26 & 5.1 & 25.7 & $17.7 \pm 5.8$ & $0.77 \pm 0.01$ & $18.2 \pm 0.8$ \\
\hline \multirow[t]{4}{*}{ S-2 } & $0 \sim 10$ & 8.34 & 33 & 7.1 & 38.6 & $39.3 \pm 8.9$ & $0.48 \pm 0.01$ & $13.6 \pm 1.0$ \\
\hline & $10 \sim 20$ & 8.38 & 26 & 6.0 & 31.6 & $36.9 \pm 9.4$ & $0.39 \pm 0.00$ & $10.1 \pm 0.6$ \\
\hline & $20 \sim 40$ & 8.51 & 28 & 5.0 & 22.2 & $17.3 \pm 6.6$ & $0.43 \pm 0.05$ & $10.5 \pm 1.7$ \\
\hline & $40 \sim 60$ & 8.80 & 26 & 4.7 & 28.0 & $32.6 \pm 1.2$ & $0.46 \pm 0.00$ & $10.3 \pm 1.4$ \\
\hline \multirow[t]{4}{*}{ S-3 } & $0 \sim 10$ & 7.54 & 38 & 6.4 & 31.0 & $39.1 \pm 11$ & $0.46 \pm 0.04$ & $18.5 \pm 0.8$ \\
\hline & 10 20 & 7.71 & 28 & 6.1 & 33.1 & $41.7 \pm 16$ & $0.40 \pm 0.01$ & $14.0 \pm 0.3$ \\
\hline & $20 \sim 40$ & 8.38 & 26 & 6.3 & 29.9 & $38.4 \pm 7.6$ & $0.46 \pm 0.03$ & $20.5 \pm 0.9$ \\
\hline & $40 \sim 60$ & 8.34 & 25 & 5.7 & 28.3 & $45.0 \pm 6.6$ & $0.35 \pm 0.01$ & $9.95 \pm 0.5$ \\
\hline \multirow[t]{4}{*}{ S-4 } & $0 \sim 10$ & 6.69 & 34 & 7.4 & 44.8 & $16.9 \pm 1.2$ & $0.41 \pm 0.01$ & $8.18 \pm 0.5$ \\
\hline & $10 \sim 20$ & 6.74 & 38 & 8.4 & 35.3 & $15.3 \pm 1.9$ & $0.41 \pm 0.01$ & $8.93 \pm 0.5$ \\
\hline & $20 \sim 40$ & 6.94 & 39 & 9.6 & 24.6 & $14.0 \pm 2.2$ & $0.40 \pm 0.01$ & $6.20 \pm 0.3$ \\
\hline & $40 \sim 60$ & 6.51 & 42 & 7.2 & 25.0 & $17.8 \pm 0.8$ & $0.38 \pm 0.01$ & $10.4 \pm 0.4$ \\
\hline \multirow[t]{4}{*}{ S-5 } & $0 \sim 10$ & 8.56 & 25 & 3.8 & 14.4 & $13.1 \pm 4.4$ & $0.52 \pm 0.01$ & $7.06 \pm 0.1$ \\
\hline & $10 \sim 20$ & 8.34 & 26 & 3.3 & 18.8 & $20.7 \pm 3.7$ & $0.53 \pm 0.02$ & $6.26 \pm 0.4$ \\
\hline & $20 \sim 40$ & 8.14 & 26 & 3.3 & 17.7 & $23.4 \pm 1.1$ & $0.54 \pm 0.01$ & $7.90 \pm 0.1$ \\
\hline & $40 \sim 60$ & 8.45 & 24 & 2.2 & 16.9 & $17.5 \pm 4.3$ & $0.56 \pm 0.03$ & $5.69 \pm 0.4$ \\
\hline S-IC & $0 \sim 20$ & 6.81 & 46 & 7.9 & 7.9 & $29.3 \pm 3.6$ & $1.70 \pm 0.03$ & $99.0 \pm 9.4$ \\
\hline
\end{tabular}

D-6 had the highest T-As among the layers which had fine silty clay to adsorb much amount of As. Paddy field site S-1, S-2 and S-3 containing high T-As in surface and subsoil among the sites seemed to be influenced by the irrigation groundwater and subsequent rise and fall in groundwater level during wet and dry season changes the As concentration in different layers. The high concentration of T-As in irrigation channel seemed to be caused by oxidation of Fe (II) to Fe (III) during irrigation and iron hydroxide particles are formed which bind As partly or completely and settles down in the channel from the flowing water. Also it enters to the paddy field and accumulates on the surface.

OM generally has a low affinity for As. Correlation between OM and T-As of paddy field samples $\left(r^{2}=0.37\right)(p<0.05)$ and pond sediment samples $\left(r^{2}=0.18\right)(p=0.07)$. OM may enhance the release of As from soils into the soil solution, thereby facilitating As leaching into the groundwater. The main influencing mechanisms include competition for available adsorption sites and changes in the redox potential of site surfaces and As redox speciation. Correlation of MC with T-As of pond sediment and paddy field samples was $\left(r^{2}=0.44\right)(p<0.05)$ and $\left(r^{2}=0.31\right)(p<0.05)$ respectively which indicated that soil water holds As in soil. Clay content of soil and T-As correlated by $\left(r^{2}=0.20\right)(p<0.05)$ and $\left(r^{2}=0.12\right)(p=0.12)$ for paddy field and pond sediment samples, respectively. The retention of As on clay depends on quantity and type of clay sized materials. For example, 
kaolinite sorbs more As from solution than vermiculite, which sorbs more As than montmorillonite [23, 24].

Significant correlation $\left(r^{2}=0.67\right)(p<0.05)$ existed between T-As and T-P of paddy field and irrigation channel soil samples probably due to As and P form similar oxyanions in soils and behave similarly in well aerated soils. Although As is known to be strongly sorbed by Fe oxide materials in soil [25-27] strong correlation was not found between T-As and T-Fe $\left(r^{2}=0.04\right)(p=0.09)$ in this study. T-Fe concentrations of the studied soil and sediment samples were too large compared to that of T-As.

\subsection{Changes in As solubility as related to reducing conditions}

Soil $\mathrm{pH}$ and redox potential are important factors affecting the mobility and adsorption of arsenic [28]. Fig. 2 shows the proportion of released As in different incubation time (0, 5, 10 and 15 days) and subsequent acid-alkali extracted fractions of sediment of (a) D-6 and soil of (b) S-3. The changes in As solubility following incubation under anaerobic conditions were pronounced. The influence of redox on As solubility in soils [29] is governed by the change of arsenate $[\mathrm{As}(\mathrm{V})]$ to arsenite [As(III)] followed by desorption and the dissolution of Fe-oxyhydroxides and concurrent release of co-precipitated arsenate.

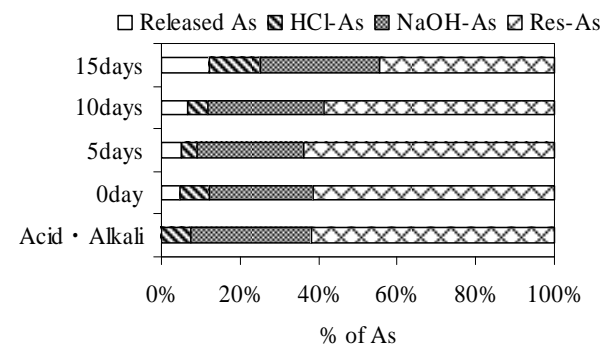

(a)

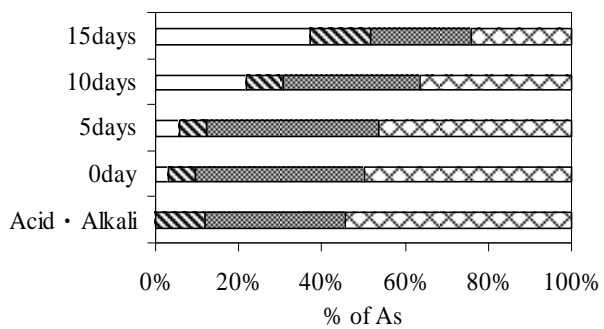

(b)

Fig. 2. Arsenic release test in different incubation period with subsequent acid-alkali sequential extraction of (a) D-6 and (b) S-3.

In zero days Eh of the soil samples was approximately $140 \mathrm{mV}$ in D-6 and $200 \mathrm{mV}$ in S-3. Eh of soil decreased to less than $-300 \mathrm{mV}$ after 15 days of incubation. $4.8 \%$ and $2.9 \%$ of T-As was released from D-6 and S-3 samples, respectively in aerobic conditions of zero days. Released As increased to 12\% in D-6 and 37\% in S-3 after 15 days of incubation. Both soil samples showed a significant increase in released As to solution with time of incubation and decreasing Eh to less than $-300 \mathrm{mV}$. Duel and Swoboda [30] reported that a reduced environment resulted in a greater soluble As concentration which supported this observation. The released As seemed to be a part of the acid extractable phases (HCl-As) of the subsequent acid-alkali extraction of the samples without the incubation (also shown in Fig. 2) that was adsorbed on the soil from soil water.

The proportion of subsequent $\mathrm{HCl}$-As after the incubation was decreased from zero to 
10 days but increased at 15 days, with respect to the proportion of $\mathrm{HCl}$-As without incubation in both soil samples. It seemed to be easily soluble fractions and dissolved in water. The proportion of $\mathrm{NaOH}-\mathrm{As}$ was increased at zero and 5 days and then decreased at 10 and 15 days of incubation with respect to without incubation in S-3. While it decreased from zero to 15 days in D-6. On the other hand, Res-As was decreased with the incubation period in the both cases. This suggested that increase of HCl-As as well as $\mathrm{NaOH}$-As in the incubated samples would be supplied from part of Res-As that seemed to be reductant soluble As and could be changed to soluble As under extremely high reducing conditions. Samples from D-IC and D-4 (results not shown) also indicated the similar observation in the same experiment.

In natural conditions, like paddy fields subjected to flooding during wet season and irrigation period and pond sediment subjected to continuous inundation for long time has the potential to release or movement of As from the surface layer to deep layer in paddy field and pond water in pond.

\subsection{Changes in As solubility as related to $\mathrm{pH}$}

The $\mathrm{pH}$ leaching experiments for As in different $\mathrm{pH}$ and subsequent acid-alkali extraction of sediment of (a) D-6 and soil of (b) S-3 are shown in Fig.3. Although the pH of the original buffer solution was adjusted to $1.0-13.0, \mathrm{pH}$ of the filtrate was little changed after 24 hrs of shaking as shown in the figure The released arsenic was $5.1 \%$ and $6.6 \%$ of T-As in around $\mathrm{pH} 2$ for D-6 and S-3, respectively. With an increase in $\mathrm{pH}$ from 3 to 6 As concentration dropped to $1.3 \%$ and $3 \%$ and further increase in $\mathrm{pH}$ to 13 increased the dissolved As to the highest which was about 33\% and 43\% for D-6 and S-3, respectively.

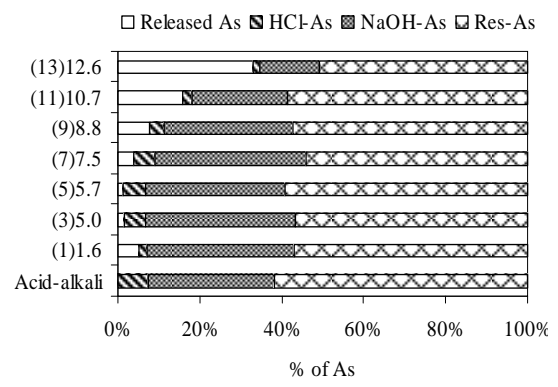

(a)

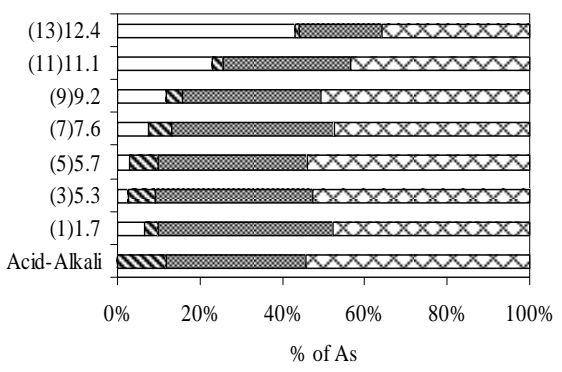

(b)

Fig. 3. Extraction of arsenic in different $\mathrm{pH}$ conditions with subsequent acid-alkali sequential extraction of (a) D-6 and (b) S-3.

The results showed a strong $\mathrm{pH}$ dependence on arsenic solubility and similar leaching profiles were reported in other studies [31, 32]. Although Fe leaching showed a similar pattern (data not shown) released less amount from the total concentration.

The amount of As and Fe leached from the soil could be attributed to either dissolution of less resistant minerals or sorption/desorption mechanisms influenced by the $\mathrm{pH}$. 
Comparing to the acid-alkali extraction without addition of buffer solution it was indicated that the dissolved As concentration at $\mathrm{pH}$ around 2 amounted to $69 \%$ and $55 \%$ of the acid extractable phases in case of D-6 and S-3 samples respectively, indicating release of weakly sorbed As on iron oxides. [29, 33, 34]. With an increase in $\mathrm{pH}$ to neutral $\mathrm{pH}$, precipitation of $\mathrm{Fe}$ as hydroxides could result in co-precipitation of As on to the solid matrix, resulting in lower concentrations of dissolved As. Further increase in $\mathrm{pH}$ beyond neutral $\mathrm{pH}$, solubility of As was increased in alkaline $\mathrm{pH}$ and $\mathrm{NaOH}$-As as well as Res-As were also dissolved. In contrast Fe release was much lower than As in alkaline conditions. As the suspension $\mathrm{pH}$ increases, hydroxyl ions replace As on the Fe oxide sorption sites, facilitating the desorption of As [29, 33, 35, 36]. Therefore it was suggested that HCl-As showed As fraction that could be dissolved in low $\mathrm{pH}$, while part of $\mathrm{HCl}-\mathrm{As}, \mathrm{NaOH}-\mathrm{As}$ and Res-As were shown to be As fraction that could be dissolved in high $\mathrm{pH}$.

Moreover, moderately reducing conditions Eh value (-150 and $-90 \mathrm{mV}$ ) (redox potential measured during the $\mathrm{pH}$ batch) in D-6 and S-3, respectively and alkaline (pH around 13) conditions observed led to more As and Fe solubilization, seemed to be due to the reductive dissolution of iron hydroxides and consequent solubilization of adsorbed As [6].

Although the results were not shown, samples from D-IC and D-4 also exhibited the similar nature in the same experiment.

Therefore, the acid-alkali sequential extraction method could be applicable to measure potential solubility of As from different solid phases as a result of alteration in soil (e.g. redox, $\mathrm{pH}$ ) and environmental factors.

\subsection{Acid-alkali extraction of As and properties of soil}

The change of extracted As by $0.1 \mathrm{~N} \mathrm{HCl}$ with time showed that extraction of As fraction was gradually increased from 3 mins to $17 \mathrm{hrs}$. The fraction in 3 mins was considered to be surficially bound with metal hydroxides and seemed to be soluble in water. While As extracted slowly in several hours by $0.1 \mathrm{~N} \mathrm{HCl}$ seemed to be calcium [12] and carbonate [37] bound As. Therefore extraction time by $0.1 \mathrm{~N} \mathrm{HCl}$ was considered to be 3 mins to measure soluble As. The change of extracted As by $0.1 \mathrm{~N} \mathrm{NaOH}$ with time exhibited almost similar as $0.1 \mathrm{~N} \mathrm{HCl}$ extract fraction. For the extraction of As held strongly by sorption to Fe components of soil surfaces 17 hours is needed for $0.1 \mathrm{~N} \mathrm{NaOH} \mathrm{[12].}$

Considerable variation occurred between sites and soil depths in the amount of As present in extracted fractions (Table 2). In spite of the variation, some general trends were apparent. The acid extractable fraction (HCl-As) was small and accounted for $<10 \%$ of the total soil As (mean $7.4 \%)$. However, subsoil $(80 \sim 100 \mathrm{~cm})$ of D-6 and surface layer $(0 \sim 20 \mathrm{~cm})$ of S-1 had higher proportion of this fraction as well as high content of T-As.

At most of the sites high proportions of total As were extracted in the $\mathrm{NaOH}$ fraction (mean 28.9\%). Amount of HCl-As was lower than that of $\mathrm{NaOH}$-As in almost all the samples. Min et al. (2005) [38] reported similar observations showing that As extracted by 
Table 2. Acid-alkali extracted amount of soil samples in dry and wet season.

\begin{tabular}{|c|c|c|c|c|c|c|c|}
\hline Site name & $\begin{array}{l}\text { Depth } \\
\text { (cm) }\end{array}$ & $\begin{array}{c}\text { HCl-As } \\
(\mu \mathrm{g} / \mathrm{g})\end{array}$ & $\begin{array}{c}\mathrm{NaOH}-\mathrm{As} \\
(\mu \mathrm{g} / \mathrm{g})\end{array}$ & $\begin{array}{l}\mathrm{HCl}-\mathrm{P} \\
\text { (mg/g) }\end{array}$ & $\begin{array}{l}\mathrm{NaOH}-\mathrm{P} \\
\text { (mg/g) }\end{array}$ & $\begin{array}{c}\mathrm{HCl}-\mathrm{Fe} \\
\text { (mg/g) }\end{array}$ & $\begin{array}{c}\mathrm{NaOH}-\mathrm{Fe} \\
\text { (mg/g) }\end{array}$ \\
\hline \multirow[t]{5}{*}{ D-1 } & $0 \sim 20$ & 0.06 & 3.02 & 0.02 & 0.04 & 0.36 & 0.56 \\
\hline & $20 \sim 40$ & 0.13 & 2.85 & 0.06 & 0.06 & 0.17 & 0.20 \\
\hline & $40 \sim 60$ & 0.28 & 2.74 & 0.13 & 0.01 & 0.22 & 0.01 \\
\hline & $60 \sim 80$ & 0.36 & 2.77 & 0.11 & 0.01 & 0.09 & 0.00 \\
\hline & $80 \sim 100$ & 0.39 & 2.62 & 0.11 & 0.01 & 0.30 & 0.00 \\
\hline \multirow[t]{5}{*}{$\mathrm{D}-2$} & $0 \sim 20$ & 0.48 & 2.25 & 0.22 & 0.06 & 0.30 & 0.01 \\
\hline & $20 \sim 40$ & 0.61 & 2.18 & 0.19 & 0.002 & 0.53 & 0.01 \\
\hline & $40 \sim 60$ & 0.50 & 2.13 & 0.20 & 0.01 & 0.44 & 0.01 \\
\hline & $60 \sim 80$ & 0.54 & 1.90 & 0.19 & 0.001 & 0.55 & 0.00 \\
\hline & $80 \sim 100$ & 0.55 & 1.91 & 0.18 & 0.001 & 0.71 & 0.00 \\
\hline \multirow[t]{5}{*}{ D-3 } & 0 20 & 0.22 & 1.65 & 0.11 & 0.05 & 0.08 & 0.06 \\
\hline & $20 \sim 40$ & 0.24 & 2.59 & 0.14 & 0.05 & 0.10 & 0.04 \\
\hline & $40 \sim 60$ & 0.32 & 2.86 & 0.15 & 0.06 & 0.10 & 0.07 \\
\hline & $60 \sim 80$ & 0.47 & 3.10 & 0.16 & 0.06 & 0.11 & 0.13 \\
\hline & $80 \sim 100$ & 0.34 & 2.22 & 0.14 & 0.004 & 0.18 & 0.01 \\
\hline \multirow[t]{5}{*}{ D-4 } & 0 20 & 0.08 & 1.98 & 0.06 & 0.08 & 0.05 & 0.09 \\
\hline & $20 \sim 40$ & 0.06 & 1.93 & 0.12 & 0.10 & 0.11 & 0.07 \\
\hline & $40 \sim 60$ & 0.08 & 1.35 & 0.14 & 0.07 & 0.11 & 0.03 \\
\hline & $60 \sim 80$ & 0.07 & 1.55 & 0.19 & 0.01 & 0.14 & 0.002 \\
\hline & $80 \sim 100$ & 0.11 & 1.48 & 0.19 & 0.03 & 0.14 & 0.00 \\
\hline \multirow[t]{5}{*}{ D-5 } & 0 20 & 0.24 & 1.82 & 0.05 & 0.05 & 0.17 & 0.01 \\
\hline & $20 \sim 40$ & 0.28 & 1.24 & 0.16 & 0.002 & 0.18 & 0.01 \\
\hline & $40 \sim 60$ & 0.35 & 1.83 & 0.16 & 0.003 & 0.22 & 0.01 \\
\hline & $60 \sim 80$ & 0.37 & 1.81 & 0.16 & 0.04 & 0.14 & 0.01 \\
\hline & $80 \sim 100$ & 0.19 & 0.88 & 0.14 & 0.001 & 0.15 & 0.01 \\
\hline \multirow[t]{5}{*}{ D-6 } & 0 20 & 0.81 & 2.00 & 0.17 & 0.04 & 0.07 & 0.13 \\
\hline & $20 \sim 40$ & 0.76 & 2.45 & 0.13 & 0.04 & 0.16 & 0.28 \\
\hline & $40 \sim 60$ & 0.83 & 1.29 & 0.20 & 0.05 & 0.08 & 0.22 \\
\hline & $60 \sim 80$ & 1.18 & 1.54 & 0.25 & 0.03 & 0.12 & 0.15 \\
\hline & $80 \sim 100$ & 3.79 & 5.30 & 0.20 & 0.04 & 0.15 & 0.30 \\
\hline D-IC & 0 20 & 4.57 & 34.8 & 0.13 & 0.38 & 1.03 & 0.19 \\
\hline \multirow[t]{4}{*}{ S-1 } & $0 \sim 10$ & 7.37 & 7.99 & 0.47 & 0.29 & 0.12 & 0.08 \\
\hline & $10 \sim 20$ & 8.48 & 10.3 & 0.49 & 0.28 & 0.35 & 0.06 \\
\hline & $20 \sim 40$ & 0.49 & 7.56 & 0.17 & 0.10 & 0.14 & 0.07 \\
\hline & $40 \sim 60$ & 2.83 & 10.3 & 0.30 & 0.19 & 0.18 & 0.07 \\
\hline \multirow[t]{4}{*}{ S-2 } & $0 \sim 10$ & 1.25 & 4.21 & 0.09 & 0.16 & 0.29 & 0.14 \\
\hline & $10 \sim 20$ & 0.23 & 2.10 & 0.08 & 0.10 & 0.11 & 0.22 \\
\hline & $20 \sim 40$ & 0.33 & 2.29 & 0.13 & 0.10 & 0.13 & 0.17 \\
\hline & $40 \sim 60$ & 0.33 & 2.57 & 0.15 & 0.01 & 0.17 & 0.15 \\
\hline \multirow[t]{4}{*}{ S-3 } & $0 \sim 10$ & 1.68 & 11.4 & 0.07 & 0.12 & 0.29 & 0.15 \\
\hline & $10 \sim 20$ & 0.84 & 4.23 & 0.06 & 0.11 & 0.10 & 0.14 \\
\hline & $20 \sim 40$ & 2.45 & 6.93 & 0.10 & 0.13 & 0.15 & 0.14 \\
\hline & $40 \sim 60$ & 0.34 & 4.40 & 0.07 & 0.08 & 0.16 & 0.15 \\
\hline \multirow[t]{4}{*}{ S-4 } & $0 \sim 10$ & 0.46 & 2.83 & 0.11 & 0.09 & 0.15 & 0.37 \\
\hline & $10 \sim 20$ & 0.41 & 2.91 & 0.11 & 0.09 & 0.13 & 0.53 \\
\hline & $20 \sim 40$ & 0.35 & 1.57 & 0.17 & 0.10 & 0.13 & 0.22 \\
\hline & $40 \sim 60$ & 1.28 & 4.53 & 0.19 & 0.09 & 0.31 & 0.18 \\
\hline \multirow[t]{4}{*}{ S-5 } & $0 \sim 10$ & 0.48 & 1.27 & 0.23 & 0.005 & 0.26 & 0.28 \\
\hline & $10 \sim 20$ & 0.51 & 1.58 & 0.25 & 0.01 & 0.27 & 0.28 \\
\hline & $20 \sim 40$ & 0.52 & 1.56 & 0.22 & 0.01 & 0.23 & 0.28 \\
\hline & $40 \sim 60$ & 0.39 & 1.14 & 0.20 & 0.003 & 0.42 & 0.28 \\
\hline S-IC & $0 \sim 20$ & 9.51 & 43.2 & 0.30 & 1.11 & 1.48 & 0.15 \\
\hline
\end{tabular}


$\mathrm{HCl}$ was much lower than that by the same concentration $(<0.5 \mathrm{M})$ of $\mathrm{NaOH}$. The As in $\mathrm{NaOH}$ fraction is likely to be associated with Fe oxide materials present in soils and previous fractionation studies of As contaminated soils have also found a predominance of Fe bound forms of As [10, 39, 40]. The relatively low proportions of HCl-As does not mean that As toxicity or mobility is unlikely to be a problem. The high proportion of $\mathrm{NaOH}$-As at depth in some soil profiles suggests a significant potential for further leaching under suitable $\mathrm{pH}$ and reducing conditions which was observed in batch release tests.

As mentioned earlier in $\mathrm{pH}$ batch test results that proportion of Fe release in acidic condition was similar to As while in alkaline conditions was less than As. The amount of extractable Fe during acid-alkali extraction shown in Table 2 supported this findings. The proportion of $\mathrm{NaOH}$ extractable $\mathrm{Fe}$ was less than $\mathrm{HCl}$ extractable in almost all samples. The relationship between extracted As and Fe was determined by linear regression. The $\mathrm{HCl}$ extractable fractions of As and Fe showed linear regression coefficients, $r^{2}$ value $\left(r^{2}=0.30\right)(p<0.05)$ while that of $\mathrm{NaOH}$ extractable showed very poor correlation $\left(r^{2}=0.004\right)(p=0.34)$.

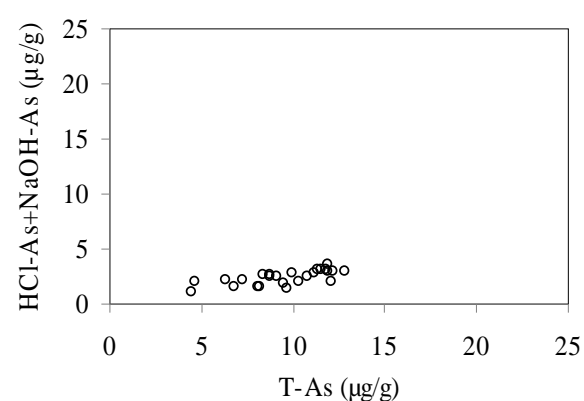

(a)

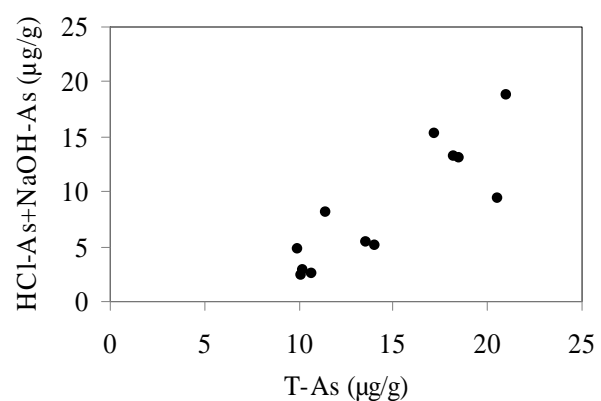

(b)

Fig. 4. Relationship between T-As and (HCl-As $+\mathrm{NaOH}-\mathrm{As}$ ) of paddy soil samples (a) dry and (b) wet season.

The correlation of T-As with the sum of HCl-As and NaOH-As was shown in Fig. 4. The difference between dry and wet samples was clear and apparent increase of T-As as well as the extracted As fractions was observed in wet season. The increase of HCl-As and $\mathrm{NaOH}$-As in the wet season exhibited that easily soluble As was supplied from irrigation water that contained high concentration of As and adsorbed on the surface of soil particles. Actually As concentration of the irrigation well water of S-3 was almost $250 \mu \mathrm{g} / \mathrm{L}$ and T-As in the soil of irrigation channel (S-IC) was around $99.0 \mu \mathrm{g} / \mathrm{g}$.

The increase in $\mathrm{HCl}$-As and $\mathrm{NaOH}$-As was more clearly noticed in the samples collected from same paddy field in dry and wet season i.e. D-1 (same as S-2), D-4 (same as S-3) and irrigation channel D-IC (same as S-IC). As for D-1 and S-2 average HCl-As content was increased from 0.24 to $0.54 \mu \mathrm{g} / \mathrm{g}$ whereas in case of D-4 and S-3 it increased from 0.08 to $1.33 \mu \mathrm{g} / \mathrm{g}$. Moreover it increased from 4.57 to $9.51 \mu \mathrm{g} / \mathrm{g}$ in case of D-IC and 
S-IC. On the other hand average $\mathrm{NaOH}-\mathrm{As}$ content was unchanged in case of D-1 and S-2, increased from 1.66 to $6.74 \mu \mathrm{g} / \mathrm{g}$ (D-4 and S-3) and 34.8 to $43.2 \mu \mathrm{g} / \mathrm{g}$ (D-IC and S-IC).

In case of pond sediment samples correlation of T-As with the sum of $\mathrm{HCl}$-As and $\mathrm{NaOH}-$ As shown in Fig. 5 indicated that T-As increased with the extracted As fractions by the correlation slope of nearly 1 suggested that the increase in T-As was contributed from the extracted As fractions.

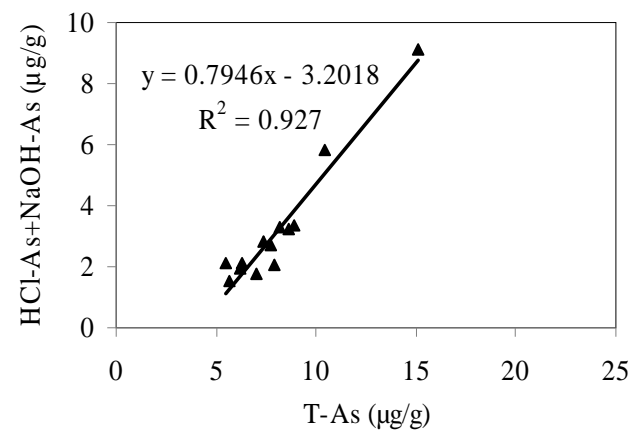

Fig. 5. Relationship between T-As and (HCl-As $+\mathrm{NaOH}-\mathrm{As})$ of pond sediment samples.

Further examination of the extraction data showed that the amounts of As in the individual fractions were generally strongly correlated with each other and with total As concentrations as in Table 3.

Table 3. Correlation coefficients $\left(\mathrm{r}^{2}\right)$ between total As and P concentrations and extracted fractions.

\begin{tabular}{llllll}
\hline & HCl-As & NaOH-As & T-P & HCl-P & NaOH-P \\
\hline T-As & $0.54^{* * *}$ & $0.95^{* * *}$ & $0.65^{* * *}$ & 0.05 & $0.88^{* * *}$ \\
HCl-As & & $0.57^{* * *}$ & $0.75^{* * *}$ & $0.48^{* * *}$ & $0.65^{* * *}$ \\
NaOH-As & & & $0.62^{* * *}$ & $0.06^{*}$ & $0.81^{* * *}$ \\
T-P & & & & $0.45^{* * *}$ & $0.76^{* * *}$ \\
HCl-P & & & & & $0.11^{* * *}$ \\
\hline
\end{tabular}

$* p<0.05, * * p<0.01, * * * p<0.001$.

As mentioned earlier that the proposed acid-alkali sequential extraction method is a procedure for the measurement of boiavailable $\mathrm{P}$ of soil. Therefore, the extracted $\mathrm{P}$ fractions of the soil samples were also measured (Table 2). Fig. 6 shows correlations of T-P with the sum of HCl-P and $\mathrm{NaOH}-\mathrm{P}$ of the paddy soil samples. The difference between dry and wet samples was clear and apparent increase of T-P as well as the 
extracted $\mathrm{P}$ fractions was observed in wet season. The increase of soluble $\mathrm{P}$ fractions seemed to be caused by irrigation water and $\mathrm{P}$ fertilization.

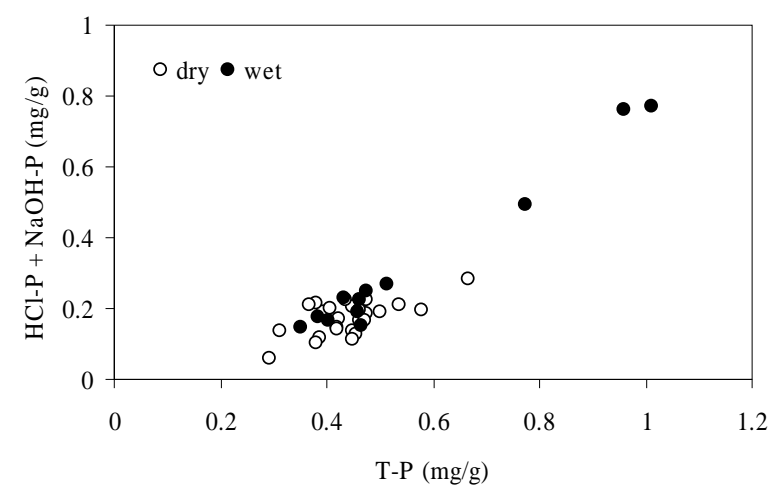

Fig. 6. Relationship between T-P and (HCl-P + NaOH-P) of paddy soil samples.

Similar to As the individual $\mathrm{P}$ fractions were correlated well with the total $\mathrm{P}$ concentrations (Table 3). Significant correlation was obtained between $\mathrm{HCl}$ and $\mathrm{NaOH}$ extracted As and $\mathrm{P}$ fractions during this study. This results indicated the similar behavior of As and P in soil. It has been reported that $\mathrm{P}$ enhanced As release in soil by competing for adsorption sites [39, 41, 42] and in As toxic soils high $\mathrm{P}$ fertilization may be a mechanism for moving some of the toxic, more soluble As deeper into the soil.

\section{Conclusion}

Relatively higher As concentration in paddy field soils specially in irrigation channel soil indicated that As accumulation occurred from the high As in irrigation water. Also P fertilizers as well as irrigation water resulted in higher concentrations of soluble P. The important findings from this study are as follows:

a. Redox potential was shown to control solubility of As in soil suspensions. Under aerobic conditions, As solubility were low. Upon reduction, As solubility increased significantly and seemed to be controlled by dissolution of Fe oxy-hydroxides.

b. $\mathrm{pH}$ played a predominant role in determining the concentrations of soluble As, with concentrations being higher in extremely low or high $\mathrm{pH}$. In acidic condition As release is influenced by the release of Fe while increase in $\mathrm{pH}$ to alkaline condition solubility of As increased due to the replacement of As by hydroxyl ions on the Fe oxide sorption sites.

c. Results of $\mathrm{pH}$ and incubation batch test with the subsequent acid-alkali extraction showed that released As was included in the extractable As fractions under 
different $\mathrm{pH}$ and redox conditions and it could be estimated by the acid-alkali extraction.

d. From examination of extraction conditions, easily soluble was measured by extraction with $50 \mathrm{~mL}$ of $0.1 \mathrm{~N} \mathrm{HCl}$ during 3 minutes followed by extraction with $100 \mathrm{~mL}$ of $0.1 \mathrm{~N} \mathrm{NaOH}$ during 17 hours to measure $\mathrm{NaOH}$-As successively.

e. T-As of surface and subsoil samples of paddy was increased in wet season that was contributed by the sum of extractable As fractions. It seemed to be moved with irrigation groundwater and carried away by rainwater or floodwater.

f. Extracted P fractions of soil samples exhibited similar trend to that of As fractions.

\section{Acknowledgments}

The authors would like to express their thanks to KUET and ADAMS for their kind cooperation in sample collection and using laboratory for this study. A part of this study was funded by KAKENHI (18560534).

\section{References}

1. R. K. Dhar, B. K. Biswas, G. Samanta, B. K. Mandal, D. Chakraborti, S. Roy, A. Jafar, A. Islam, G. Ara, S. Kabir, A.W. Khan, S. A. Ahmed, and S. A. Hadi, Current Sci. 73, 48 (1997).

2. F. W. Pontius, J. Am. Water Works Assoc. 90 (3), 38 (1998).

3. M. M. Karim, Water Res. 34 (1), 304 (2000). doi:10.1016/S0043-1354(99)00128-1

4. M. J. Abedin, J. Cotter-Howells, and A. A. Mehrag, Plant Soil 240, 311(2002). doi:10.1023/A:1015792723288

5. J. Arnt, K. Rudnitski, B. Schmidt, L. Speelman, and S. Nobouphasavanh, Earth and Atmosphere Field Camp 87 (1997).

6. R. T. Nickson, J. M. McArthur, P. Ravenscroft, W. G. Burgess, and K. M. Ahmed, Appl. Geochem. 15, 403 (2000). doi:10.1016/S0883-2927(99)00086-4

7. A. Tessier, P. G. C. Campbell, and M. Bisson, Anal. Chem. 51, 844 (1979). doi:10.1021/ac50043a017

8. Z. S. Ahnstrom, and D. R. Parker, Soil Sci. Soc. Am. J. 63, 1650 (1999).

9. X. L. Qiao, Y. M. Luo, P. Christie, and M. H. Wong, Chemosphere 50, 823 (2003). doi:10.1016/S0045-6535(02)00226-6

10. L.W. Jacobs, J. K. Syers, and D. R. Keeney, Soil Sci. Soc. Am. Proc. 34, 750 (1970).

11. E. A. Woolson, J. H. Axley, and P. C. Kearney, Soil Sci. Soc. Am. Proc. 35, 938 (1971).

12. R. G. McLaren, R. Naidu, J. Smith, and K. G. Tiller, J. Environ. Qual. 27, 348 (1998).

13. P. O’Neill, Heavy metals in soils. In B. J. Alloway (ed.) Arsenic, (John Wiley \& Sons, New York,1990) pp. 83-99.

14. R. D. Wauchope, J. Environ. Qual. 4, 355 (1975).

15. L. M. Shuman, Soil Sci. Soc. Am. J. 46, 1099 (1982).

16. T. T. Chao, and L. Zhou, Soil Sci. Soc. Am. J. 47, 225 (1983).

17. K. A. Gruebel, J. A. Davis, and J. O. Leckie, Soil Sci. Soc. Am. J. 52, 390 (1988).

18. J. Nakajima, and T. Okubo, BAP measurement using successive extraction by acid and alkali. Diffuse Pollution Conference (Dublin, 2003).

19. M. F. Ahmed, Soil environment and arsenic contamination of groundwater in Bangladesh - Proc. of Int. Conf. on Geoenvironment (Sultan Qabus University, Oman, 2000) pp. 256-264.

20. G. C. Saha and M. A. Ali, Science of the Total Environment, in press, available online 24 
October (2006).

21. M. Chen, L. Q. Ma, and W. G. Harris, Soil Sci. Soc. Am. J. 66, 632 (2002).

22. A. A. Mehrag and M. M. Rahman, Environ. Sci. Technol. 37, 229 (2003). doi:10.1021/es0259842

23. S. Goldberg and R. A. Glaubig, Soil Sci. Soc. Am. J. 52, 1297 (1988).

24. B. M. Onken and D. C.Adriano, Soil Sci. Soc. Am.J. 61, 746 (1997).

25. P. M. Huang, Soil Sci. Soc. Am. J. 39, 271 (1975).

26. S. Goldberg, Soil Sci. Soc. Am. J. 50, 1154 (1986).

27. G. T. Vaughan, CET/LHIR148, NSW, Australia (1993).

28. P. L. Smedley and D. G. Kinniburgh, App. Geochem. 17, 517 (2002). doi:10.1016/S0883-2927(02)00018-5

29. P. H. Masscheleyn, R. D. Dlaune, and W. H. Patrick Jr., Environ. Sci. Technol. 25, 1414 (1991). doi:10.1021/es00020a008

30. L. E. Duel and A.R. Swoboda, Soil Sci. Soc. Am. J. 36, 276 (1972).

31. F. Sanchez, A. C. Garrabrants, D. S. Kosson, and H. A. Van Der Sloot, EPA/625/R-03/010, Dec. 2003, p. 77.

32. Souhail R Al-abed, G. Jegsdeesan, J. Purandare, and D. Allen, Chemosphere 66, 775 (2007). doi:10.1016/j.chemosphere.2006.07.045

33. M. L. Pierce and C. B. Moore, Water Res. 16, 1247 (1982).

34. R. Bayard, V. Chatain, C. Gachet, A. Troadec, and R. Gourdon, Water Res. 40, 1240 (2006). doi:10.1016/j.watres.2006.01.025

35. S. E. Fendorf, M. J. Eick, P. Grossl, and D. L Sparks, Environ. Sci. Technol. 31, 315 (1997). doi:10.1021/es950653t

36.J. K Yang, M. O. Barnett, P. M. Jardine, N. T. Basta, and S.W. Casteel, Environ. Sci. Technol. 36, 4562 (2002). doi:10.1021/es011507s

37. J. Shiowatana, R. G. McLaren, N. Chanmekha, and A. Samphao, J. Environ. Qual. 30, 1940 (2001).

38. J. Min, S. H. Jung, I. C. Sang, and K. P. Jae, Chemosphere 60, 344 (2005). doi:10.1016/j.chemosphere.2004.12.018

39. E. A. Woolson, J. H. Axley, and P. C. Kearney, Soil Sci. Soc. Am. Proc. 35, 938 (1971).

40. E. A. Woolson, J. H. Axley, and P. C. Kearney, Soil Sci. Soc. Am. Proc. 35, 101 (1971).

41. B. Manning and S. Goldberg, Soil Sci. Soc. Am. J. 60, 121 (1996).

42. F. Liu, A. De Cristofaro, and A. Violante, Soil Science 166 (3), 197 (2001). doi:10.1097/00010694-200103000-00005 